\title{
One-step purification of cholesterol oxidase from culture broth of a Pseudomonas sp. using a novel affinity chromatography method
}

\author{
HAe-IK Rhee, ${ }^{1 *}$ KyUng-Jin JeOng, ${ }^{2}$ Boo-KIL PARK, ${ }^{2}$ Yong-SOON ChOI ${ }^{1}$ and SANG-Young LeE ${ }^{2}$ \\ ${ }^{1}$ Department of Applied Biology and Technology and ${ }^{2}$ Department of Food Science and Technology, Kangweon National \\ University, Chuncheon 200-701, Republic of Korea
}

(Received 24 September 1990; revised 31 January 1991; accepted 13 February 1991)

\begin{abstract}
Cholesterol oxidase from the culture broth of a Pseudomonas sp. was purified with a yield of more than $70 \%$ by a one-step procedure using a column of cholesterylglycine-carboxymethylcellulose; active enzyme was eluted by Triton X-100. The purified enzyme was homogeneous by SDS-PAGE.
\end{abstract}

\section{Introduction}

Cholesterol oxidase (EC 1.1.3.6) catalyses the oxidation of cholesterol (5-cholesten-3 $\beta$-ol) to 4-cholesten-3-one with the reduction of oxygen to hydrogen peroxide. This enzyme has been widely used for determination of cholesterol in clinical specimens by coupling with peroxidase (Richmond, 1973; Allain et al., 1974). We have previously described a Pseudomonas sp. that produces extracellular cholesterol oxidase (Lee et al., 1989). In this report we describe the synthesis of a novel cholesterol affinity adsorbent and a very simple purification procedure that gives a high yield of homogeneous cholesterol oxidase from culture broth of this Pseudomonas sp. This procedure eliminates laborious steps in the conventional purification procedures.

\section{Methods}

\begin{abstract}
Organism and growth. The cholesterol-oxidase-producing microorganism Pseudomonas sp. COX629 was grown under the conditions described previously (Lee et al., 1989).

Synthesis of cholesterylglycine. The following procedure was used. A mixture of Cbz-glycine $(2 \cdot 1 \mathrm{~g})$ and cholesterol $(3 \cdot 8 \mathrm{~g})$ in chloroform $(50 \mathrm{ml})$ was cooled to $0{ }^{\circ} \mathrm{C}$; dicyclohexylcarbodiimide $(2 \cdot 1 \mathrm{~g})$ was then added and the mixture was stirred at $0^{\circ} \mathrm{C}$. After $5 \mathrm{~h}$, the solvent was evaporated under reduced pressure and the residue was dissolved in ethyl acetate. After filtration, the filtrate was successively washed with $1 \mathrm{M}-\mathrm{HCl}$, saturated $\mathrm{NaHCO}_{3}$ solution and saturated $\mathrm{NaCl}$ solution, and dried over $\mathrm{Na}_{2} \mathrm{SO}_{4}$. It was then purified by preparative silica gel thin layer chromatography using n-hexane/ethyl acetate $(2: 1, \mathrm{v} / \mathrm{v})$ as the solvent. For deprotection of the benzyloxycarbonyl group, the product was dissolved in ethyl acetate and hydrogenated in the presence of palladium charcoal at room temperature for $3 \mathrm{~h}$. After
\end{abstract}

Abbreviation: KPB, potassium phosphate buffer. filtration, the solvent was removed under reduced pressure. Cholesterylglycine was prepared as a syrup, and used for the next step without further purification. About $500 \mathrm{mg}$ cholesterylglycine was added to $250 \mathrm{ml}$ dimethylformamide and mixed with $15 \mathrm{~g}$ of CM-cellulose. The $\mathrm{pH}$ of this suspension was adjusted to $4 \cdot 6$ with $2 \mathrm{M}-\mathrm{HCl}$. 1-Ethyl-3-(3dimethylaminopropyl)carbodiimide $(5 \mathrm{~g})$ in $5 \mathrm{ml}$ of water was added to the suspension and the reaction was allowed to proceed at room temperature overnight. Then the substituted celluiose was successively washed with $500 \mathrm{ml}$ ethyl acetate, $500 \mathrm{ml}$ chloroform and $500 \mathrm{ml}$ ethanol. About $10 \mu \mathrm{mol}$ cholesterylglycine was bound per $\mathrm{g}$ of adsorbent as shown by alkaline hydrolysis (Fukuyama \& Miyake, 1979).

Purification of cholesterol oxidase. Culture broth $(500 \mathrm{ml})$ of the Pseudomonas sp. was centrifuged at $16000 \mathrm{~g}$ for $10 \mathrm{~min}$ and the clear supernatant obtained was used for purification of the enzyme. The supernatant was directly loaded onto a column $(2.5 \times 16 \mathrm{~cm})$ of cholesterylglycine-CM-cellulose, prepared as described above, previously equilibrated with $10 \mathrm{~mm}$-potassium phosphate buffer (KPB; $\mathrm{pH} 7.5$ ) at a flow rate of $1 \mathrm{ml} \mathrm{min}^{-1}$. After washing the column with $200 \mathrm{ml} \mathrm{KPB}$ and $300 \mathrm{ml} \mathrm{KPB}$ containing $500 \mathrm{~mm}-\mathrm{KCl}$, cholesterol oxidase was eluted with a linear gradient of Triton X-100 (0-0.1\%, $600 \mathrm{ml}$ ).

Analytical methods. Protein was determined by the Lowry method. Cholesterol oxidase activity was assayed by the method of Allain et al. (1974): 1 unit of cholesterol oxidase activity was defined as the amount of enzyme that catalysed the formation of $1 \mu \mathrm{mol} \mathrm{H}_{2} \mathrm{O}_{2} \min ^{-1}$ at $37^{\circ} \mathrm{C}$. PAGE in the presence of SDS was done by the method of Laemmli (1970).

Chemicals. Benzyloxycarbonyl(Cbz)-glycine, cholesterol, 1-ethyl-3(3-dimethylaminopropyl)carbodiimide, dicyclohexylcarbodiimide, CM-cellulose, chloroform and dimethylformamide were purchased from Sigma.

\section{Results and Discussion}

Fig. 1 represents a typical elution profile from a cholesterylglycine-CM-cellulose column, showing protein concentration and cholesterol oxidase activity. Only 


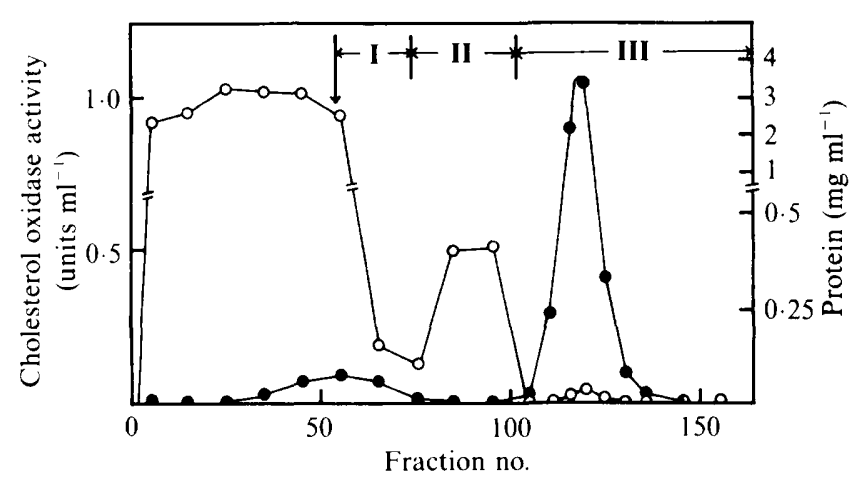

Fig. 1. Elution profile from the cholesterol oxidase affinity column. Cholesterol oxidase activity; $O$, protein. At the point indicated by the arrow, the column was washed with $200 \mathrm{ml} \mathrm{KPB}$ (I) followed by $300 \mathrm{ml}$ $\mathrm{KPB}+500 \mathrm{~mm}-\mathrm{KCl}(\mathrm{II})$; then the enzyme was eluted with a linear gradient of Triton X-100 (III ; 0-0.1\%,600 ml). (For I, II and III the flow rate was $1 \mathrm{ml} \mathrm{min}-1$ and $10 \mathrm{ml}$ fractions were collected.)

a very small amount of activity was detected in the flowthrough fractions. After eluting with a linear gradient of Triton X-100, cholesterol oxidase from the Pseudomonas sp. culture broth was purified approximately 2600 -fold with a yield of more than $70 \%$. The purified enzyme was homogeneous by SDS-PAGE, and had the same properties as those of the enzyme purified by a conventional procedure (data not shown). By using a $78.5 \mathrm{ml}$ cholesterylglycine CM-cellulose column, about $500 \mathrm{ml}$ of the culture broth can be treated. The column can be used at least twenty times without any significant loss of adsorbing activity. In coupling cholesterylglycine and CM-cellulose, glycine and the carboxymethyl group are condensed by peptide bond formation and play the role of spacer between matrix and ligand. In this system, carboxymethylglycine offers an effective spacer arm six atoms in length.

Various methods have been reported for purifying cholesterol oxidase from different species, based on enzyme-substrate specificity (Richmond, 1973; Uwajima et al., 1973; Tomioka et al., 1976; Kamei et al., 1978; Fukuyama \& Miyake, 1979; Inoue et al., 1982). Richmond (1973), Kamei et al. (1978) and Inoue et al. (1982) reported the purification of cholesterol oxidase by cholesterol affinity chromatography. In their methods, a cholesterol slurry was directly packed into a column. These methods seem not to be appropriate to large-scale purification, since binding capacity was low and solubility of the adsorbent in detergent was high. Thus it is not easy to handle and preparation of the adsorbent is expensive. Fukuyama \& Miyake (1979) purified cholesterol oxidase by affinity chromatography using 3-Osuccinylcholesterolethylenediamine-Sepharose gels.
However, the main problem in large-scale purification systems is the compressibility of the matrix materials.

Affinity chromatography can provide the most elegant method for the purification of a protein from a complex mixture. However, affinity chromatography has not generally been used for large- or industrial-scale enzyme purification because in most cases matrices are expensive, have low capacity and frequently tend to be unstable. The novel affinity absorbent described here is advantageous in three respects: (i) CM-cellulose is cheaper even than agarose beads, and therefore financial costs are less for a large-scale enzyme purification process; (ii) the characteristic fast flow rate of cellulose solves the flow rate problems that occur upon scale-up: and (iii) it is stable. This purification procedure, therefore, provides a large amount of cholesterol oxidase with a great economy in labour required for purification.

The authors thanks J. Hiratake, the Chemical Institute, Kyoto University, for helpful discussions and advice during the organic synthesis. This work was supported in part by a Grant-in-Aid for Genetic Engineering Research from the Ministry of Education of Korea.

\section{References}

Allain, C. C., Poon, L. S., Chan, C. S. G., Richmond, W. \& Fu, P. C. (1974). Enzymatic determination of total serum cholesterol. Clinical Chemistry 20, 470-475.

Fukuyama, M. \& Miyake, Y. (1979). Purification and some properties of cholesterol oxidase from Schizophyllum commune with covalently bound flavin. Journal of Biochemistry 85, 1183-1193.

Inoue, Y., Taguchi, K., Fuji, A., Ishimaru, K., Nakamura, S. \& Nomi, R. (1982). Purification and characterization of extracellular $3 \beta$-hydroxy steroid oxidase produced by Streptoverticillium cholesterolicum. Chemical Pharmacology Bulletin 30, 951-958.

KameI, T., Takiguchi, Y., Suzuki, H., Matsuzaki, M. \& NaKamura, S. (1978). Purification of $3 \beta$-hydroxysteroid oxidase of Streptomyces violescens origin by affinity chromatography on cholesterol. Chemical Pharmacology Bulletin 26, 2799-2804.

LAEMmLi, U. K. (1970). Cleavage of structural proteins during the assembly of the head of bacteriophage T4. Nature, London 227. 680-685

LeE, S. Y., Rhee, H. I., TAe, W. C., Shin, J. C. \& Park, B. K. (1989). Purification and characterization of cholesterol oxidase from Pseudomonas sp. and taxonomic study of the stain. Applied Microbiology and Biotechnology 31, 542-546.

RichmoND, W. (1973). Preparation and properties of bacterial cholesterol oxidase from Nocardia sp. and its application to the enzymatic assay of total cholesterol in serum. Clinical Chemistry 19 $1350-1356$.

Tomioka, H., Kagawa, M. \& NaKamura, S. (1976). Some enzymatic properties of $3 \beta$-hydroxysteroid oxidase produced by Streptomyces violescens. Journal of Biochemistry 79, 903-915.

Uwajima, T., Yagi, H., Nakamura, S. \& Terada, O. (1973). Isolation and crystallization of extracellular $3 \beta$-hydroxysteroid oxidase of Brevibacterium sterolicum nov. sp. Agricultural and Biological Chemistry 37, 2345-2350. 